\title{
A Case of Cutaneous Non-Mycobacterium Infection after Illegal Botulinum Toxin Injection Diagnosed by Polymerase Chain Reaction
}

\author{
Min Je Jung*, Bo Young Chung*, Yong Won Choi, Jee Hee Son, Hye One Kim, Chun Wook Park \\ Department of Dermatology, Hallym University Kangnam Sacred Heart Hospital, Seoul, Korea
}

\begin{abstract}
Dear Editor:
A 68-year-old female patient visited our clinic with severe painful and itching skin lesion around chins three months ago. On the physical examination, several erythematous to brownish round shaped papules and nodules were observed (Fig. 1A, B). She had received botulinum toxin injection on both jaws illegally elsewhere 7 months previously, not by a medical doctor. Foreign body granuloma, furuncle, and cutaneous tuberculosis (TB) were clinically suspected and a punch biopsy was performed. Upon histopathologic examination, inflammatory cell infiltration and granulomatous inflammation were observed in the dermis (Fig. 2A). Acid fast bacilli stain was negative. Initially, both Mycobacterium tuberculosis (MTB) and non-tuberculous mycobacteria (NTM) were negative in polymerase chain reaction (PCR).

In order to rule out the possibility of TB infection, TB-specific Ag induced IFN-gamma testing was performed. The result was positive and the patient was sent to the pulmonary medicine department but pulmonary TB was not suspected by chest high resolution computed tomography. Then, re-biopsy was subsequently performed to exclude cutaneous TB or NTM. From the histopathologic examination at re-biopsy, MTB-PCR was negative, but NTM-PCR was positive (Fig. 2B). Finally, the patient was diagnosed
\end{abstract}

with cutaneous NTM. The microorganism was not detected in the test for identification of the microorganism. The patient was subsequently treated with clarithromycin and levofloxacin, and large lesions on both cheeks were surgically excised. After two months of treatment, lesions were significantly improved (Fig. 1C, D). We received the patient's consent form about publishing all photographic materials.

NTM refers to mycobacterium except for MTB and leprosy bacteria ${ }^{1}$. Although cutaneous NTM is rare, the incidence is increasing due to advances in diagnostic methods such as PCR and increased invasive cosmetic procedures ${ }^{2-4}$. Typical skin lesion is erythematous nodule, but clinical presentation may be variable including ulcers and abscess $^{2}$. Identification of mycobacterium species from cultures of skin biopsies is the standard diagnostic method. PCR and DNA sequencing can be used to identify the exact subtypes ${ }^{5}$. The histologic findings may be present in various forms, such as abscess, necrosis, granuloma, and inflammatory cells infiltration ${ }^{1}$. Treatments regimens are not well established. Tetracyclines, macrolides, quinolones, and co-trimoxazoles are the most commonly used drugs ${ }^{2,4}$. In our case, we initially suspected skin TB infection due to the history of illegal botulinum toxin injection, but the result of PCR was negative from the initial biopsy specimen.

Received December 11, 2017, Revised March 22, 2018, Accepted for publication April 6, 2018

Corresponding author: Chun Wook Park, Department of Dermatology, Hallym University Kangnam Sacred Heart Hospital, College of Medicine, Hallym University, 1 Singil-ro, Yeongdeungpo-gu, Seoul 07441, Korea. Tel: 82-2-829-5221, Fax: 82-2-832-3237, E-mail: dermap@hanmail.net ORCID: https://orcid.org/0000-0003-4512-8668

Hye One Kim, Department of Dermatology, Hallym University Kangnam Sacred Heart Hospital, College of Medicine, Hallym University, 1 Singil-ro, Yeongdeungpo-gu, Seoul 07441, Korea. Tel: 82-2-829-5221, Fax: 82-2-832-3237, E-mail: hyeonekim@gmail.com ORCID: https://orcid.org/0000-0001-5846-0008

*These authors contributed equally and should be considered co-first authors.

This is an Open Access article distributed under the terms of the Creative Commons Attribution Non-Commercial License (http://creativecommons.org/ licenses/by-nc/4.0) which permits unrestricted non-commercial use, distribution, and reproduction in any medium, provided the original work is properly cited.

Copyright (C) The Korean Dermatological Association and The Korean Society for Investigative Dermatology 

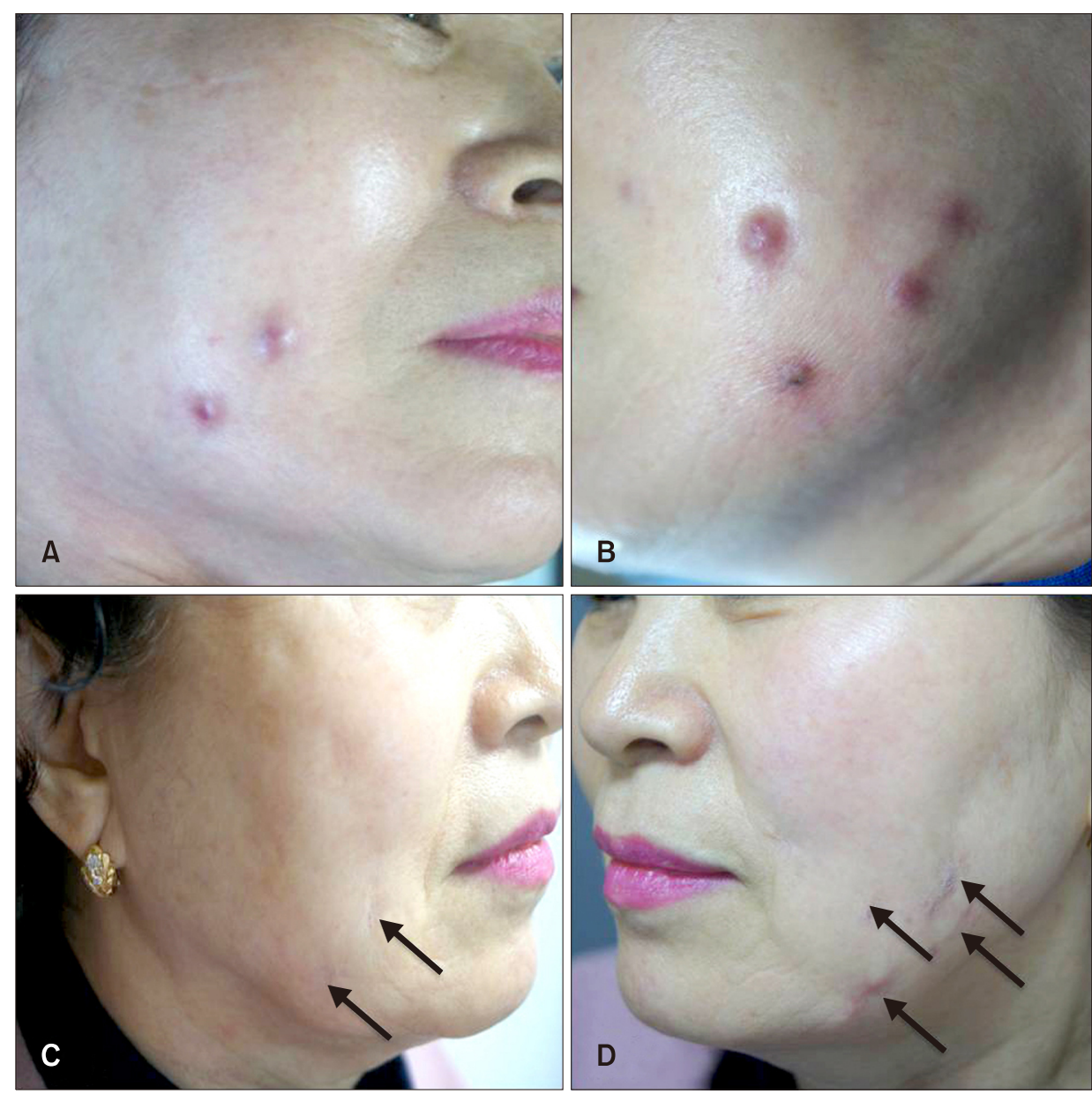

Fig. 1. (A, B) Several erythematous to brownish round shaped papules and nodules were observed on both cheeks. (A) Right cheek, (B) Left cheek. The large lesions were surgically removed via punch biopsies. The removed sites are indicated by arrows. (C, D) After treatment of two months, the lesions were improved. (C) Right cheek, (D) Left cheek.
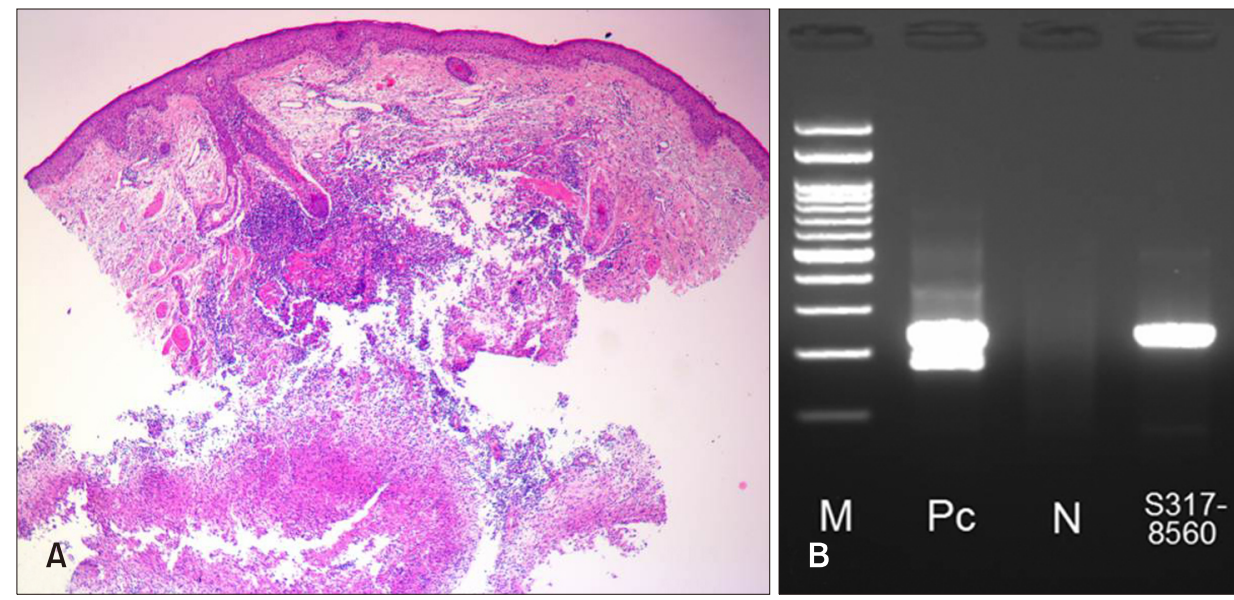

Fig. 2. (A) In the histology of the first biopsy, inflammatory cells infiltration and granulomatous inflammation was observed in the dermis $(\mathrm{H} \& \mathrm{E}, \times 40)$. (B) From the histopathologic examination at second biopsy, NTM-PCR was positive. NTM: non-tuberculous mycobacteria, PCR: polymerase chain reaction, $\mathrm{M}$ : size marker, Pc: positive control, N: negative control.

However, re-biopsy was performed based on the clinical feature and patient's history of illegal cosmetic procedure. NTM-PCR was positive in the re-biopsy specimen and eventually diagnosis of cutaneous NTM was established. Due to the trend that the prevalence of cutaneous NTM is increasing because of the illegal cosmetic procedure, the possibility of NTM infection should be considered for skin lesion that does not respond to initial treatment at the site of invasive procedures. It is helpful to perform culture and biopsy repeatedly if necessary, as we were able to successfully diagnose NTM through repeated biopsy. In this context, we report a case of cutaneous NTM that may serve as a useful educational case. 


\section{ACKNOWLEDGMENT}

This study was supported by grants of the National Research Foundation of Korea (NRF), funded by the Ministry of Science, ICT \& Future Planning (NRF-2017R1A2B400 6252), Korea Healthcare technology R\&D project, funded by Ministry of Health \& Welfare, Republic of Korea (HI17 C0597), and the Hallym University Research Fund (HURF2017-35, HURF-2017-52, HURF-2017-83).

\section{CONFLICTS OF INTEREST}

The authors have nothing to disclose.

\section{ORCID}

Min Je Jung, https://orcid.org/0000-0002-1037-2209

Bo Young Chung, https://orcid.org/0000-0002-2795-0140

Yong Won Choi, https://orcid.org/0000-0003-0607-5145

Jee Hee Son, https://orcid.org/0000-0002-7816-1942

Hye One Kim, https://orcid.org/0000-0001-5846-0008

Chun Wook Park, https://orcid.org/0000-0003-4512-8668

\section{REFERENCES}

1. Byun YS, Son JH, Cho YS, Yang YS, Cho HJ, Chung BY, et al. Cutaneous mixed infection of mycobacterium fortuitum and mycobacterium intracellulare after a fat graft. Korean J Dermatol 2016;54:459-463.

2. Lamb RC, Dawn G. Cutaneous non-tuberculous mycobacterial infections. Int J Dermatol 2014;53:1197-1204.

3. Bodle EE, Cunningham JA, Della-Latta P, Schluger NW, Saiman L. Epidemiology of nontuberculous mycobacteria in patients without HIV infection, New York City. Emerg Infect Dis 2008;14:390-396.

4. Lin SS, Lee CC, Jang TN. Soft tissue infection caused by rapid growing mycobacterium following medical procedures: two case reports and literature review. Ann Dermatol 2014;26:236-240.

5. Ngan GJ, Ng LM, Jureen R, Lin RT, Teo JW. Development of multiplex PCR assays based on the 16S-23S rRNA internal transcribed spacer for the detection of clinically relevant nontuberculous mycobacteria. Lett Appl Microbiol 2011; 52:546-554.

\title{
A Case of Perinevoid Alopecia on the Scalp
}

\author{
Seok Min Kim, Chihyeon Sohng, Jun Young Kim, Yong Hyun Jang, Seok-Jong Lee, Weon Ju Lee
}

Department of Dermatology, School of Medicine, Kyungpook National University, Daegu, Korea

\section{Dear Editor:}

Perinevoid alopecia is one of the atypical hair loss disorders $^{1}$. We describe a rare case of perinevoid alopecia. A 33-year-old woman presented with a solitary patch of alopecia with a central skin-colored papule on her vertex for
2 months (Fig. 1A). The match-head-sized skin-colored papule was observed when she was 10 years old, although the patch of alopecia was observed 2 months prior to presentation. Broken hairs were seen at the site of the patch of alopecia. There was no history of local irritation

Received December 11, 2017, Revised March 13, 2018, Accepted for publication April 9, 2018

Corresponding author: Weon Ju Lee, Department of Dermatology, Kyungpook National University Hospital, 130 Dongdeok-ro, Jung-gu, Daegu 41944, Korea. Tel: 82-53-420-5838, Fax: 82-53-426-0770, E-mail: weonju@knu.ac.kr ORCID: https://orcid.org/0000-0001-5708-1305

This is an Open Access article distributed under the terms of the Creative Commons Attribution Non-Commercial License (http://creativecommons.org/ licenses/by-nc/4.0) which permits unrestricted non-commercial use, distribution, and reproduction in any medium, provided the original work is properly cited.

Copyright (c) The Korean Dermatological Association and The Korean Society for Investigative Dermatology 